\title{
Twentieth century increase of Scots pine radial growth in NE Spain shows strong climate interactions
}

\author{
J. MARTÍNEZ-VILALTA*†, B. C. LÓPEZ*, N. A DELL $\ddagger$ L. BADIELLA $\ddagger$ and M. NINYEROLA $\S$ \\ ${ }^{*}$ CREAF/Unitat d'Ecologia, Universitat Autònoma de Barcelona, Edifici C (Facultat de Ciencies), 08193 Bellaterra, Barcelona, \\ Spain, $\uparrow$ School of GeoSciences, University of Edinburgh, Edinburgh EH9 3JN, UK, †Servei d'Estadística, Universitat Autònoma de \\ Barcelona, 08193 Bellaterra, Barcelona, Spain, §Department of Animal Biology, Plant Biology and Ecology, Universitat Autònoma \\ de Barcelona, 08193 Bellaterra, Barcelona, Spain
}

\begin{abstract}
Stem radial growth responds to environmental conditions, and has been widely used as a proxy to study long-term patterns of tree growth and to assess the impact of environmental changes on growth patterns. In this study, we use a tree ring dataset from the Catalan Ecological and Forest Inventory to study the temporal variability of Scots pine (Pinus sylvestris L.) stem growth during the 20th century across a relatively large region (Catalonia, NE Spain) close to the southern limit of the distribution of the species. Basal area increment (BAI) was modelled as a function of tree size and environmental variables by means of mixed effects models. Our results showed an overall increase of $84 \%$ in Scots pine BAI during the 20th century, consistent with most previous studies for temperate forests. This trend was associated with increased atmospheric $\mathrm{CO}_{2}$ concentrations and, possibly, with a general increase in nutrient availability, and we interpreted it as a fertilization effect. Over the same time period, there was also a marked increase in temperature across the study region $\left(0.19^{\circ} \mathrm{C}\right.$ per decade on average). This warming had a negative impact on radial growth, particularly at the drier sites, but its magnitude was not enough to counteract the fertilization effect. In fact, the substantial warming observed during the 20th century in the study area did not result in a clear pattern of increased summer drought stress because of the large variability in precipitation, which did not show any clear time trend. But the situation may change in the future if temperatures continue to rise and/or precipitation becomes scarcer. Such a change could potentially reverse the temporal trend in growth, particularly at the driest sites, and is suggested in our data by the relative constancy of radial growth after ca. 1975, coinciding with the warmer period. If this situation is representative of other relatively dry, temperate forests, the implications for the regional carbon balance would be substantial.

Keywords: basal area increment (BAI), climate change, climate-growth responses, $\mathrm{CO}_{2}$ fertilization, dendroecology, drought, Pinus sylvestris (Scots pine), tree growth, tree rings, water availability
\end{abstract}

Received 29 January 2008; revised version received 22 May 2008 and accepted 30 May 2008

\section{Introduction}

Atmospheric changes, including human-induced increases in carbon dioxide concentration, nitrogen deposition, and temperature, are likely to have a large impact on tree and forest growth. The effect of increased

Correspondence: Jordi Martínez-Vilalta, CREAF/Unitat d'Ecologia, Universitat Autònoma de Barcelona, Edifici C (Facultat de Ciències), 08193 Bellaterra, Barcelona, Spain, tel. + 3493 5811920, fax + 3493 5814151, e-mail: Jordi.Martinez.Vilalta@ uab.es
$\mathrm{CO}_{2}$ on forests can be either direct $\left(\mathrm{CO}_{2}\right.$ fertilization) or via the corresponding increase in surface temperature and associated changes in the water cycle and the distribution of precipitation (Boisvenue \& Running, 2006). There is ample evidence showing that sudden, step changes in $\mathrm{CO}_{2}$ concentrations can have dramatic impacts on plant physiology and growth in the short term (Ceulemans \& Mousseau, 1994), but the long-term effects of $\mathrm{CO}_{2}$ enhancement on natural forests are much less clear (cf. Körner, 2006, Huang et al., 2007). The longterm effect of other anthropogenic changes, such as increased $\mathrm{N}$ availability due to higher $\mathrm{N}$ deposition Journal compilation (C) 2008 Blackwell Publishing Ltd 
and other modifications of the $\mathrm{N}$ cycle, is even less clear, although recent evidence suggests that it can be substantial (Magnani et al., 2007).

Global warming has also the potential to increase tree growth, particularly in northern and temperate latitudes (Saxe et al., 2001). However, these potentially positive effects of global change interact with water availability, and have to be considered together with the changes in the water balance (Weltzin et al., 2003). In that respect, it is important to consider that climate change is predicted to result in an increase in the frequency and intensity of droughts (IPCC, 2007), particularly in areas such as the Mediterranean basin (e.g. Sumner et al., 2003). All these atmospheric changes have also the potential to affect tree demography and community composition and structure; so at longer time scales these effects should be considered together with the direct effects of atmospheric changes on tree and ecosystem physiology.

In water-limited ecosystems, the response of trees to rising $\mathrm{CO}_{2}$ and temperature is likely to be mediated by rainfall dynamics and by two interactions. Firstly, because air temperature controls atmospheric water demand, any increase in temperature without a corresponding increase in water availability will enhance water stress, potentially reducing tree growth (Aber et al., 2001). Secondly, greater $\mathrm{CO}_{2}$ concentrations promote increased water-use efficiency and changes in biomass allocation that allow trees to save water, potentially ameliorating water stress (Wullschleger et al., 2002). Because these two interactions have opposite sign, the net effect of these atmospheric changes is particularly difficult to predict, and may change depending on the species considered, the local climate, and the current year conditions.

Stem radial growth for any given year often integrates the effect of current and previous year's climate. For this reason, tree rings have been widely used as a proxy to study long-term patterns of tree growth and to assess the impact of environmental changes on growth patterns, based on the general assumption that the climate-tree growth relationships remain approximately constant over time (Fritts, 1976). Time series of ring widths have been used to identify historical $\mathrm{CO}_{2}$ growth enhancements in several Quercus and Pinus species (Soulé \& Knapp, 2006; Voelker et al., 2006), to recognize changes in the sensitivity of tree growth to climate (Carrer \& Urbinati, 2006; Andreu et al., 2007), to study the regional variability of the climate-tree growth relationships within a species (Piovesan et al., 2005; Carrer et al., 2007), or to identify recent growth declines due to reduced water availability in Mediterranean regions (Jump et al., 2006; Sarris et al., 2007).
Tree ring data has particular characteristics. Firstly, ring width is affected by a complex set of potential explanatory variables (climate, $\mathrm{CO}_{2}$, nutrient availability, etc.) and their interactions (Fritts, 1976). Secondly, tree ring series are temporally autocorrelated or, in other words, they correspond to repeated measures on each tree. Finally, individual trees, or groups of trees within a site, often respond in different ways, due to small-scale variation in climate, nutrient availability, soils, or past history (e.g. forest management). This combination of factors makes mixed models, in which fixed and random effects can be effectively accounted for, particularly well suited to analyse tree ring data series (Budhathoki et al., 2008).

Scots pine (Pinus sylvestris L.) is one of the most widely distributed trees on Earth. Despite the fact that the largest populations of this species occur in boreal regions, Scots pine also occupies large areas in relatively dry regions within the Mediterranean basin, from the Iberian Peninsula to Turkey. The Spanish populations of Scots pine constitute the southern limit of the species' range, which makes these populations particularly interesting as systems where to study the impacts of climatic changes, because the current climatic conditions at these southern populations may be representative of the conditions under which Scots pine will grow in northern populations during the current century. Many European Scots pine populations have suffered high mortality rates associated with recent drought episodes, including populations in Spain (MartínezVilalta \& Piñol, 2002; Hódar et al., 2003) and at higher latitudes (Rebetez \& Dobbertin, 2004; Bigler et al., 2006).

In this paper, we use tree ring data from the Catalan Ecological and Forest Inventory (IEFC; Burriel et al., 2000-2004) to study the temporal variability of Scots pine stem radial growth (period 1901-1997) across a relatively large region (Catalonia, NE Spain) situated close to the southern limit of the distribution of the species. The study area includes contrasting climates, ranging from relative cold and humid locations in the Pyrenees to warmer and drier locations towards the south, providing a particularly rich study system. The main aims of the paper are, first, to determine whether growth has changed over time and, second, to relate the changes in growth to changes in the driving environmental variables across space and time. In order to achieve this, we used a novel approach based on mixed effects models with an explicit description of the relationship between tree size and growth, and its variability across sites and trees. It was hypothesized that: (1) Scots pine growth would be promoted under high temperature and $\mathrm{CO}_{2}$ concentrations; and (2) the effects of temperature and $\mathrm{CO}_{2}$ would interact with water availability in space and time, so that (a) the positive 
effect of temperature on stem growth will tend to be less, or even reversed, during dry years and/or at dry sites; whereas (b) the fertilization effect of $\mathrm{CO}_{2}$ would be promoted under drier conditions due to its positive effect on water-use efficiency.

\section{Material and methods}

\section{The IEFC dataset}

The collection of tree rings used in this study was obtained between 1988 and 1998 by the Centre for Ecological Research and Forestry Applications (CREAF) as part of the IEFC (Burriel et al., 2000-2004; http:/ / www.creaf.uab.es/iefc/). This inventory included a total of 10664 plots randomly distributed throughout the forested area of Catalonia, NE Spain (1 214408 ha of forest). Scots pine was present in 3219 (30.2\%) of those plots, and was the dominant tree species in 1962 plots (18.4\% of all sampled plots). The total estimated area of Scots pine forests in Catalonia is 219754 ha, being the second most abundant tree species in the region after Pinus halepensis. In Catalonia, Scots pine is distributed preferably on north-facing slopes between 800 and $1600 \mathrm{~m}$ a.s.1. In plots where Scots pine was dominant, its average density was 903 trees ha ${ }^{-1}$, the average basal area was $21.6 \mathrm{~m}^{2} \mathrm{ha}^{-1}$, the average canopy height was $13.1 \mathrm{~m}$, and the average tree age was 49 years (Burriel et al., 2000-2004).

Tree rings were sampled in a random subset of approximately $20 \%$ of the IEFC plots. In each of those plots the dominant species was sampled (see Burriel et al., 2000-2004 for details). Cores were extracted with an increment borer from trees covering the whole tree diameter range represented in the plot. Trees within a plot were selected to represent a given diameter class, and these were sampled proportionally to their abundance in the plot. On each tree, one single core extending the whole stem from north to south was extracted at approximately $0.5 \mathrm{~m}$ height. Cores were placed in wooden supports and taken to the laboratory for analysis. In the laboratory, all cores were air dried, fixed to the support, and smoothed by sanding with progressively finer grade sandpaper until growth rings could be easily recognized. Ring width was measured to the nearest $0.01 \mathrm{~mm}$ using a binocular scope and a linear table attached to a PC (CATRAs system; Aniol, 1983).

\section{Data selection and quality control}

From the original IEFC dataset, we selected all the plots where Scots pine was dominant (Scots pine basal area $>80 \%$ of the total plot basal area), and where at least five cores had been sampled from Scots pine trees. The software COFECHA (Grissino-Mayer, 2001) was used to check the consistency of the different ring-width time series within plots. Only those trees showing positive correlations with the other trees in the plot were kept for further analysis. Subsequently, the dataset was filtered again so that only the plots with at least five sampled trees were retained. A final filtering was carried out to remove the trees that were very small at the time of sampling [Diameter at Breast Height $(\mathrm{DBH})<10 \mathrm{~cm}]$, those showing extreme changes in radial growth (due to core reading errors or to growth releases), and those for which the reconstruction of past diameters lead to inconsistent results (e.g. because the wood cores did not reach the centre of the tree). The final database contained 548 trees from 135 plots (Fig. 1), spanning the period 1751-1997. The average length of the time period covered by the growth series obtained for each plot was 54 years. Although this fact clearly limits the sample size at the beginning of the study period (early 20th century; Fig. 3a), it is a reflection of the age structure of current Scots pine forests in Catalonia and is, to an important degree, unavoidable.

The resulting ring-width time series were not detrended, because our main aim was to detect the effect of environmental changes, and these changes coincided in time with any age trends occurring in the studied trees (cf. Jump et al., 2006; Sarris et al., 2007; see the following text for details).

\section{Climatic and carbon dioxide records}

Two climatic datasets were used, the first one to characterize the spatial variability in climate across the study region, and the second one to characterize the temporal changes. The former was created by modelling climatic surfaces from discrete climatic data from the Spanish weather-monitoring system (National Weather Institute; http://www.inm.es). All weather stations in Catalonia with available data were included in the analysis. The time period was limited to January 1951-December 1998, because before 1951 the number of weather stations was not enough to achieve reasonable accuracy in the model predictions. Multiple regressions with residual correction, together with spatial interpolation based on inverse distance weighting and splines, were used to predict monthly and annual values of precipitation and minimum, maximum, and mean temperature with a spatial resolution of $180 \mathrm{~m}$ (cf. Ninyerola et al., 2007a,b). The procedure was implemented in a Geographic Information System (GIS) environment. The explanatory variables were altitude, latitude, continentality (linear distance to Mediterranean and Atlantic coasts), potential solar radiation, and terrain curvature - all derived from a digital 


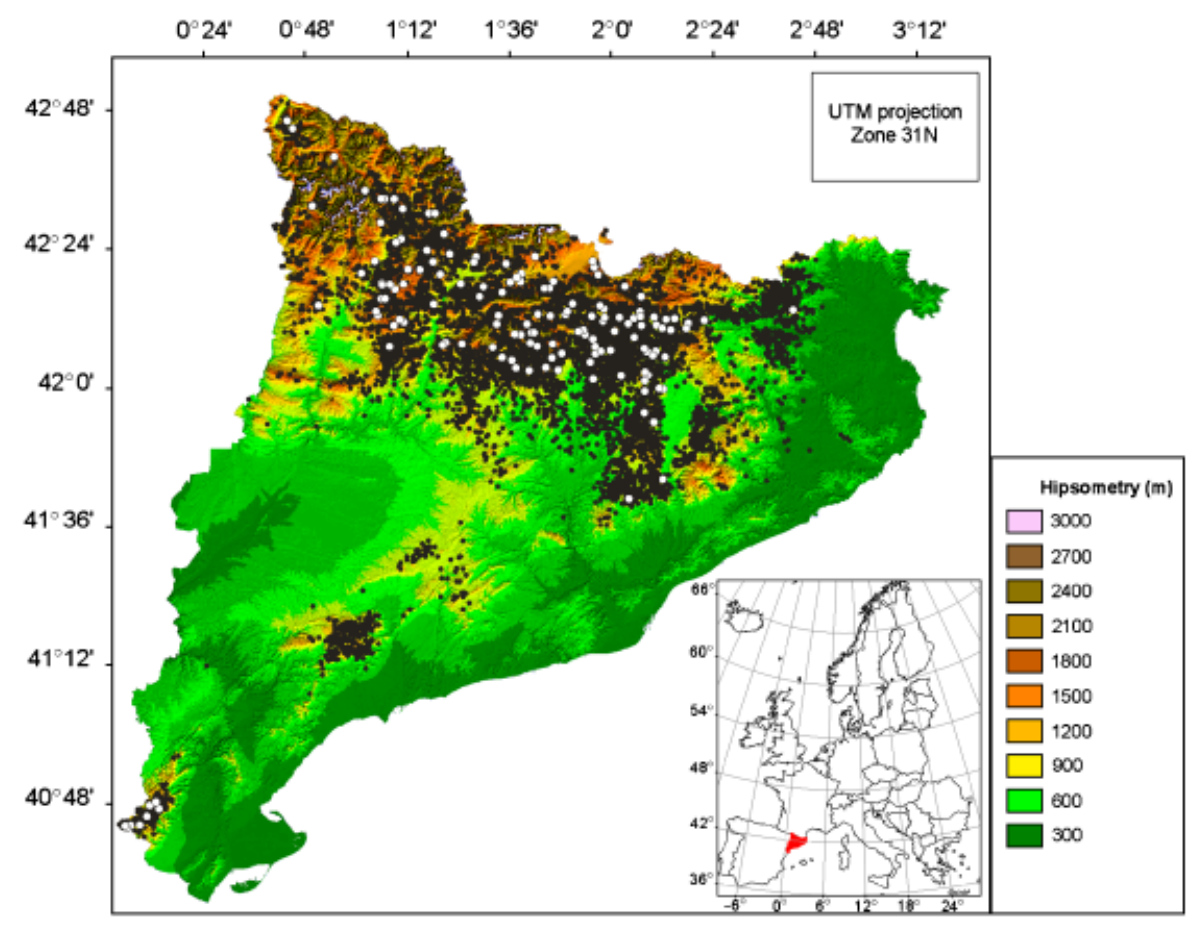

Fig. 1 Map of Catalonia showing hypsometry, the distribution of Pinus sylvestris (black dots), and the distribution of the sapling plots considered in the study (white dots).

elevation model. The total number of weather stations used was 47-201 for temperature and 170-370 for precipitation, depending on the year. A fraction of these stations (40\%) was not included in the development of the model and was used only afterwards for crossvalidation purposes. The average root mean square (RMS) error for the monthly data was $1.3^{\circ} \mathrm{C}$ for temperature and $22 \mathrm{~mm}$ for precipitation. These errors are comparable with those obtained by current climaticmapping efforts using spatial interpolation tools (Ninyerola et al., 2007a, b; Cristóbal et al., 2008).

Monthly potential evapotranspiration (PET) was calculated from monthly values of minimum, maximum, and mean temperature using the Hargreaves-Samani method (Hargreaves \& Samani, 1982). The average (1951-1998) values of mean annual temperature, annual precipitation, annual PET, and the average ratio of precipitation $(P)$ to PET for June-August (summer $P / \mathrm{PET}$, a measure of summer drought stress) were used to characterize the climate of each plot. The studied plots covered a wide range of environmental conditions, with average annual temperatures ranging from 5.7 to $12.4^{\circ} \mathrm{C}$, annual precipitation ranging between 750 and $1220 \mathrm{~mm}$, and summer $P /$ PET between 0.38 and 0.94 .

The CRU TS 1.2 dataset (Mitchell \& Jones, 2005) was used to characterize the temporal trends in climate across the study region. This gridded dataset comprises the period 1901-2000, and has a spatial resolution of $10^{\prime}$.
Monthly values of temperature and precipitation for the cells containing each of the study plots were extracted from the general dataset, and PET was calculated as described earlier. The CRU dataset includes constant daily temperature oscillations for each cell for the period 1901-1950. Because this is unrealistic, more accurate estimates of these oscillations were obtained from the linear relationship between the monthly averages of daily temperature oscillation and average monthly temperature from the 1951-1998 dataset based on climatic surfaces (see earlier text). Average values across all the study plots of mean annual temperature, annual precipitation, annual PET, and summer P/PET were used to characterize the temporal variation in climate for the study period 1901-1997.

Average annual $\mathrm{CO}_{2}$ concentrations were computed from monthly values taken from two sources: the historical $\mathrm{CO}_{2}$ record from the Law Dome DE08, DE08-2, and DSS ice cores (period 1900-1978) and the Mauna Loa record (from 1958 onwards) (both records are available at http://cdiac.ornl.gov/). The congruency between the two records was assessed by comparing the common 1958-1978 period for which the average difference between the two was $0.75 \mathrm{ppm}$. Because other anthropogenic changes are likely to have lead to increased nutrient availability over the 20th century in the study area (e.g. nitrogen deposition; Camarero et al., 2004), the record of $\mathrm{CO}_{2}$ concentrations 
used here should be regarded as a proxy for increased nutrient availability.

\section{Growth modelling and data analyses}

Basal area increment (BAI) was used to characterize tree growth. BAI was calculated from tree ring growth according to:

$$
\mathrm{BAI}=\pi\left(R_{t}^{2}-R_{t-1}^{2}\right),
$$

where $R$ is the radius of the tree and $t$ is the year of tree ring formation. Because any measure of tree growth, including BAI, varies with tree size and age, we first modelled ontogenetic changes in BAI as a function of tree diameter. We used a measure of tree size instead of tree age because evidence is accumulating for many tree species, including Scots pine, supporting that changes in tree growth after maturation are mostly driven by changes in tree size, rather than by age per se (cf. Mencuccini et al., 2005).

The distribution of BAIs was strongly skewed to the left. Accordingly, this variable was normalized by applying natural logarithms, and $\ln (\mathrm{BAI})$ was used as the response variable in all the following analyses. Mixed effects models (maximum likelihood method) were used to analyse the effect of environmental variables on tree growth. The general structure of the models can be summarized as:

$$
Y_{i}=X_{i} \beta+Z_{i} b_{i}+\varepsilon_{i},
$$

where $Y_{i}$ is the vector containing the values of $\ln (\mathrm{BAI})$ for tree $i, X_{i}$ corresponds to the matrix of fixed effects, $\beta$ is the vector of parameters associated to the fixed effects, $Z_{i}$ is the design matrix of random effects, $b_{i}$ is the matrix containing the vectors of parameters corresponding to the random effects, and $\varepsilon_{i}$ is the vector of error terms for tree $i$. The random effects were assumed to follow a normal distribution with zero mean.

In a first approximation, $\ln (\mathrm{BAI})$ was modelled as a quadratic function of tree diameter $(D)$ plus a set of random factors, including the individual tree, the plot, and the interaction between the individual tree and the linear and quadratic terms of the diameter effect (Model 0 ). The residuals of this model did not show any pattern, and it was used as a basis for all the following models.

The second step of our analysis was to explore the temporal trends, first by explicitly introducing time as an explanatory variable in the basic model (Model 1), and then by removing time and introducing the environmental variables one by one as fixed factors. This procedure contrasts the individual contribution of each of these variables to the variation in growth. These explanatory variables included atmospheric $\mathrm{CO}_{2}$ concentration, annual temperature, annual precipitation, annual PET, and summer P/PET ratio (Models $2 \mathrm{a}-2 \mathrm{e}$, respectively). These variables summarize reasonably independent aspects that have been identified in previous studies as the most important determinants of tree growth (cf. Fritts, 1976). The selection of explanatory variables also responded to a compromise with the availability of reliable data and considerations on the relevant time frame in the context of the study. For instance, we used annual climatic temperature and precipitation averages, instead of monthly or seasonal values, because there were small geographic differences in the detailed response functions across sites. These different responses would have added confusion to the overall patterns reported in this study, and a detailed analysis of those geographic patterns, which we are currently carrying out, is well beyond the scope of this paper.

To account for the presence of lags in the response of growth to meteorological variables (e.g. Sarris et al., 2007), we computed additional variables by averaging the data of the last 2 and 3 years (including current year data). The fits of the models with these lagged variables were compared with the fit with the current year data, and whenever the lagged variable improved significantly the overall fit it was selected for use in all further analyses. Finally, a single composite model was build using all environmental variables and second-order interactions, and retaining only the significant effects (Model 3).

The third step was to explicitly account for spatial variability across the sites. In order to do that, we conducted an extra analysis in which we split our plots according to their summer $P / P E T$ to clarify the differences between dry and humid sites. This was done by introducing an additional dummy variable with three levels coding for local climate. The categorization was done based on the distribution of the average (19511998 period) of summer $P / P E T$ values for each plot so that the sites belonging to the lower quartile $(P / \mathrm{PET}<0.6 ; N=28$ plots) were considered dry, those in the upper quartile ( $P / \mathrm{PET}>0.8, N=28$ plots) were considered humid, and the rest (interquartilic range) were deemed intermediate. We tested the interaction of this dummy variable representing local climate with both annual temperature and summer P/PET (Model 4). Finally, the possible interaction between the effect of $\mathrm{CO}_{2}$ and local dryness was accounted for by adding an additional term to Model 4 describing the interaction between $\mathrm{CO}_{2}$ and local climate (Model 5).

The possible effect of forest management on the results was assessed by introducing a dichotomic management variable based on the field observations recorded during the IEFC sampling and documented in 
the dataset. Because no historic information was available for most plots, our definition was based on the evidences at the time of sampling, and included two different criteria. According to the first one, a forest was deemed 'managed' if there was any evidence of current or past forest management or of major land-use changes at the time of sampling (including tree cutting and presence of terraces indicating land abandonment) (56\% of plots). According to a second criterion, only plots with evidences of directed management (mostly tree cutting) were considered as 'managed' (52\% of plots).

When we aimed at describing the individual relationship between growth and a given explanatory variable included in the previous models, the effect of the variable was always depicted considering only the fixed part of the model (i.e. without taking into account the random effects). All figures showing predicted model effects have to be considered descriptive rather than predictive. Analyses were conducted with SAS system (v. 9.1.3, SAS Institute Inc., Cary, NC, USA). Significance for all statistical analyses was accepted at $\alpha=0.05$. The $R^{2}$ of mixed models was estimated using a likelihood ratio statistic (Magee, 1990).

\section{Results}

Average annual temperature increased significantly in the study area over the period 1901-1997 $\left(R^{2}=0.457\right.$, $P<0.001)$. The overall increase in temperature was almost $2{ }^{\circ} \mathrm{C}\left(0.19^{\circ} \mathrm{C}\right.$ per decade on average), mostly noticeable during the period 1920-1950 and after 1970 (Fig. 2a). As a consequence, annual PET also increased over time $\left(R^{2}=0.220, P<0.001\right.$; data not shown). In contrast, precipitation varied around $960 \mathrm{~L} \mathrm{~m}^{-2}$ without showing any consistent trend with time (Fig. 2b; $P=0.254$ ). Surprisingly, the ratio of precipitation to PET for the summer months did not change over time following the annual temperature and PET patterns (Fig. 2c; $P=0.865$ ), because the wide, approximately random variation in precipitation overcame the increase, relatively small in absolute terms, in temperature and PET. BAI increased over the study period (Fig. $3 b)$, but as the average age and size of the trees also changed, we explicitly modelled the effect of size on growth before interpreting this pattern.

The initial model relating BAI and tree diameter (Model 0) captured the shape of the relationship between the two variables. The estimate of the first-order coefficient was positive, whereas the second-order coefficient was negative, implying a decline in BAI for larger trees (Table 1). When time (year) was introduced into the model, the fit improved significantly. The best estimate for the time effect was positive, reflecting that,
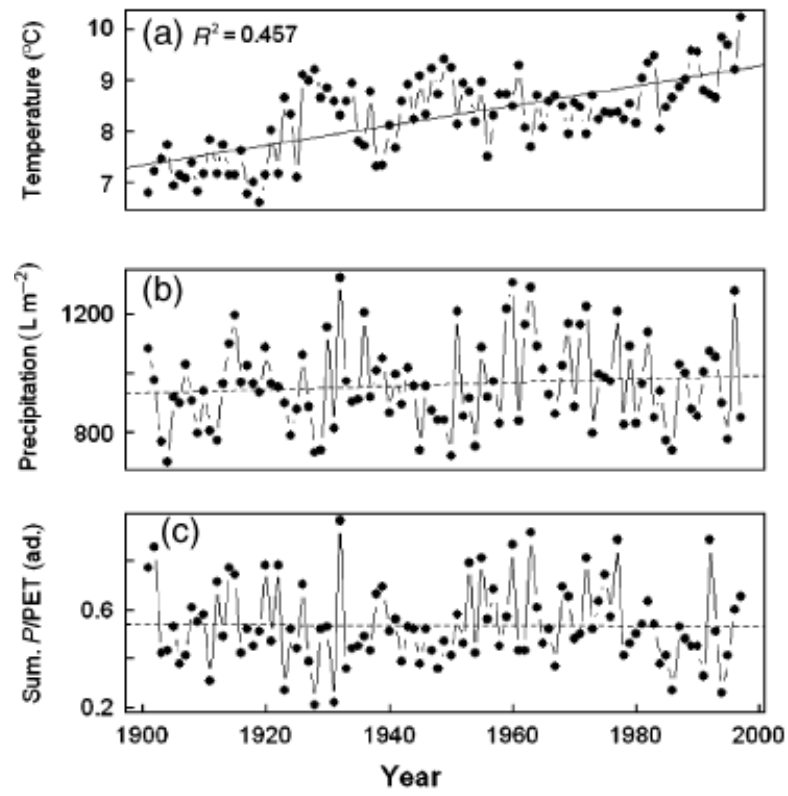

Fig. 2 Average temporal trends (1901-1997) of temperature (a), precipitation (b), and summer precipitation to potential evapotranspiration ratio $(P / \mathrm{PET})(\mathrm{c})$ for all the study plots. Only significant $R^{2}$ values are shown.

on average, BAI growth increased over time (Table 1). Taking into account the effects of tree size (i.e. running the model with constant tree diameter over time), the predicted increment in BAI between the 1901-1910 average and the 1990-1996 average was $120 \%,>84 \%$ increase corresponding to the data in Fig. 3, or the $89 \%$ predicted by the model with variable tree diameter. This result implies that the change in growth was not due to changes in the size (or age) of the trees, but primarily caused by some external variable changing over time. In the following paragraphs, we explore the underlying variables that could explain this change in growth.

In the next step, time was removed from the model and environmental variables were introduced one by one (Models 2a-2e). In a preliminary analysis, we compared the fit of the model with current year or lagged data (average of the previous 2 or 3 years, including the current one). The results of these analyses showed that $\ln (\mathrm{BAI})$ correlated equally well with current temperature than with the average of current and previous year data (not shown). For the other climatic variables (precipitation, PET, and summer $P / \mathrm{PET}$ ), the fit was best with the average of current and previous year data (not shown), and this lagged variable was used in all further analyses. As expected, the coefficients of the 'single-factor' models were positive for $\mathrm{CO}_{2}$, precipitation and summer $P / \mathrm{PET}$, meaning that 
these variables were positively related to growth, whereas the relationship was negative with temperature and PET (Table 1).

When all environmental variables were introduced, the best model [lower AIC (Akaike Information Criterion $=27156]$ was the one incorporating the effect of $\mathrm{CO}_{2}$, summer $P / \mathrm{PET}$, temperature, and the interaction between temperature and summer P/PET (Model 3, $R^{2}=0.680$, Table 2 ). This interaction implied that when
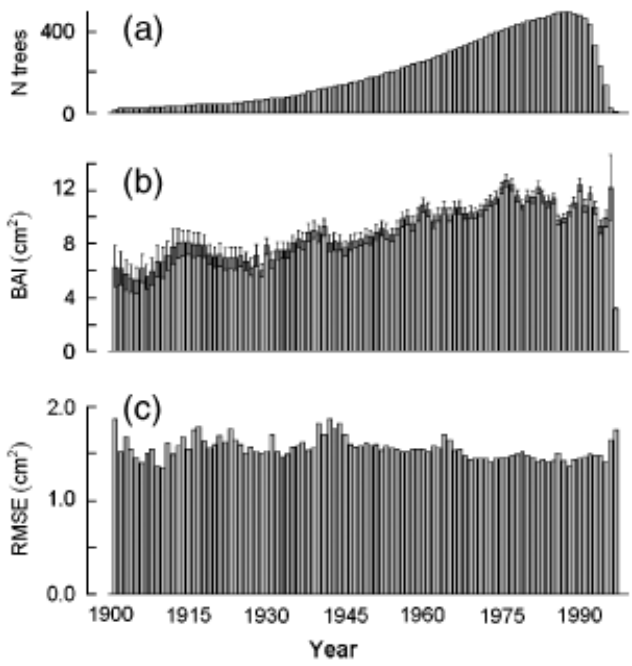

Fig. 3 Number of trees (a) and basal area increment (BAI) (b) as a function of time for the whole study period (1901-1997). (c) Root mean squared error (RMSE) of modelled BAI (according to Model 3, Table 2) against measured values, showing that the observed temporal patterns are captured by the model. Error bars in (b) indicate standard errors. summer $P /$ PET was high (relatively wet summers with $P /$ PET $>\sim 0.7$ ), temperature had a slightly positive effect on BAI, whereas when summer P/PET was low (dry summers with $P / P E T<\sim 0.7$ ), increasing temperature had the opposite effect, strongly reducing BAI (Fig. 4). Conversely, summer P/PET had a strong and positive effect on BAI growth in years with high temperatures, whereas it had almost no effect on growth during colder years (for annual temperatures $<7{ }^{\circ} \mathrm{C}$ ) (Fig. 4).

As expected, absolute BAI growth was greater ( $\sim 50 \%$ on average) at more humid sites (Fig. 5). More interestingly, there was a significant interaction between the effect of climatic variables in Model 3 and the

Table 2 Summary of the composite model (Model 3, see text)

\begin{tabular}{lrlrr}
\hline Fixed effects & Estimate & \multicolumn{1}{l}{$\mathrm{SE}$} & \multicolumn{1}{l}{$\mathrm{df}$} & $P$-value \\
\hline Intercept & -1.6863 & 0.3944 & 134 & $<0.001$ \\
$D$ & 0.1634 & 0.0086 & 543 & $<0.001$ \\
$D^{2}$ & -0.0059 & 0.0003 & 539 & $<0.001$ \\
$\mathrm{CO}_{2}$ & 0.0103 & 0.0009 & 18634 & $<0.001$ \\
Summer P/PET (2) & -1.1505 & 0.4456 & 18634 & 0.001 \\
Temperature (c) & -0.1271 & 0.0291 & 18634 & $<0.001$ \\
Summer P/PET & 0.1833 & 0.0522 & 18634 & $<0.001$ \\
$\quad \times$ Temperature & & & & \\
\hline
\end{tabular}

Note: The response variable is the natural logarithm of BAI. $D$ is tree diameter reconstructed from wood cores, PET is potential evapotranspiration, and $P$ is precipitation. For climatic effects, (c) indicates that the current year values were used, whereas (2) indicates that the average between current and previous year values were used.

Table 1 Summary of the models based on Eqn (2) (see text)

\begin{tabular}{|c|c|c|c|c|c|c|}
\hline Model & Model AIC & Fixed effect & Estimate & SE & $\mathrm{df}$ & $P$-value \\
\hline $0: \sim D+D^{2}$ & 27446 & Intercept & 0.8466 & 0.1004 & 134 & $<0.001$ \\
\hline $0: \sim D+D^{2}$ & & $D$ & 0.1408 & 0.0081 & 543 & $<0.001$ \\
\hline $0: \sim D+D^{2}$ & & $D^{2}$ & -0.0042 & 0.0003 & 539 & $<0.001$ \\
\hline 1: $0+$ Time & $27374^{* * *}$ & Time & 0.0090 & 0.0010 & 18637 & $<0.001$ \\
\hline 2a: $0+\mathrm{CO}_{2}$ & $27393^{* * *}$ & $\mathrm{CO}_{2}$ & 0.0070 & 0.0009 & 18637 & $<0.001$ \\
\hline 2b: $0+$ Temperature & $27416^{* * *}$ & Temperature (c) & -0.0365 & 0.0064 & 18637 & $<0.001$ \\
\hline 2c: $0+P$ & $27385^{* * *}$ & Precipitation (2) & 0.0003 & $<0.0001$ & 18637 & $<0.001$ \\
\hline 2d: $0+$ PET & $27438^{* *}$ & $\operatorname{PET}(2)$ & -0.0737 & 0.0228 & 18637 & 0.0012 \\
\hline 2e: $0+P /$ PET & $27282^{* * *}$ & Summer $P /$ PET (2) & 0.3795 & 0.0294 & 18637 & $<0.001$ \\
\hline
\end{tabular}

Note: In all cases the response variable is the natural logarithm of basal area increment (BAI), and the explanatory variables correspond to annual averages, except for summer $P$ /PET. Models are nested so that all the fixed factors in Model 0 are included in Model 1 and in Models 2a-e. $D$ is tree diameter reconstructed from wood cores, PET is annual potential evapotranspiration, and $P$ is annual precipitation. For climatic effects, (c) indicates that the current year values were used, whereas (2) indicates that we used the average between the current year and the year before. AIC stands for Akaike Information Criterion.

Statistically significant differences (improvements) with regard to the basal model (Model 0) are marked with asterisks; ${ }^{* *}: 0.01<P<0.001,{ }^{* * *}: P<0.001$. 

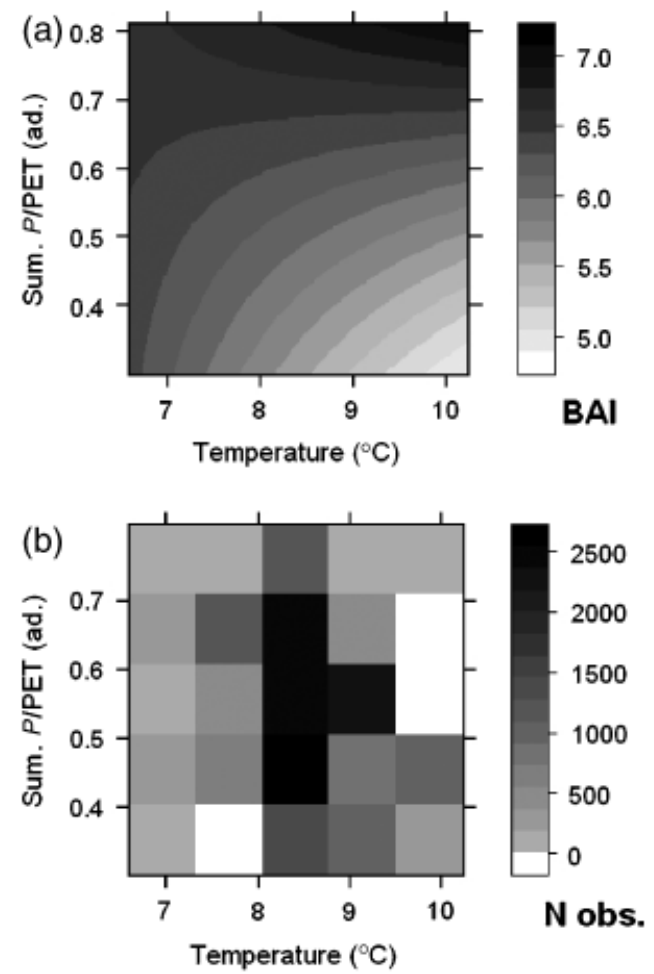

Fig. 4 (a) Surface plot showing the predicted effect (Model 3, see text) of temperature and summer precipitation to potential evapotranspiration ratio $(P / \mathrm{PET})$ on $\mathrm{BAI}$ (combining all stands). Only the fixed part of the model was used to illustrate the effects. (b) Surface plot showing the number of observations available for each combination of temperature and summer $P / P E T$ values, and thus an indication of the reliability of the model in different regions of the parameter space explored in panel (a).

long-term average local climate. In particular, the effect of annual temperature was different depending on the dryness of the site (Model $4, R^{2}=0.686$, Table 3). Whereas at wet sites (average summer $P /$ PET $>0.8$ ), increasing annual temperature promoted growth during relatively humid years and had the opposite effect during drier years (Fig. 5a); at dry sites (average summer $P /$ PET $<0.6$ ), the effect of increasing temperature was always detrimental to growth, particularly during dry years (Fig. 5b). Qualitatively similar effects were observed when the interaction between summer $P /$ PET and local $P /$ PET was included into the model instead of the annual temperature $\times$ local $P / P E T$ interaction, although the overall fit of the model declined slightly (new $\mathrm{AIC}=21157$, compared with $\mathrm{AIC}=21153$ of Model 4).

The final step was introducing the interaction between the effect of $\mathrm{CO}_{2}$ and local climate into the model. This interaction was again significant and improved significantly the overall fit of the model (Model 5, AIC $=21143$, $R^{2}=0.694$, Table 4), with a greater effect of $\mathrm{CO}_{2}$ on
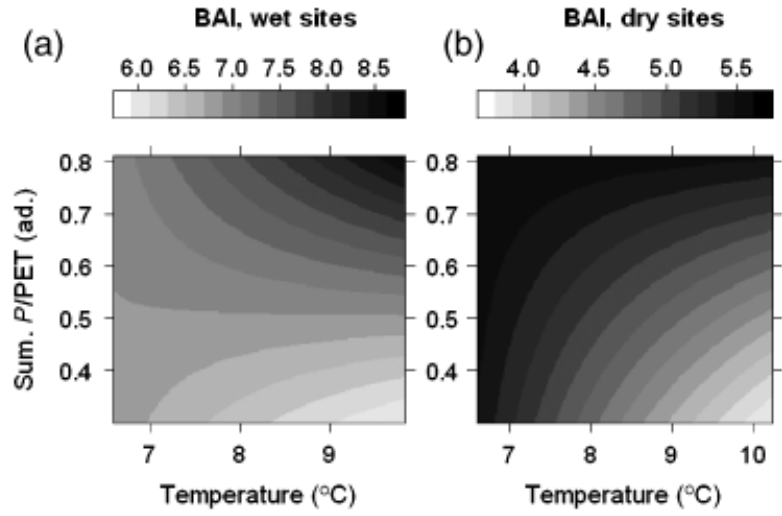

Fig. 5 Surface plots showing the predicted effect (Model 4, see text) of temperature and summer precipitation to potential evapotranspiration ratio $(P / P E T)$ on BAI for (a) wet sites (summer $P /$ PET $>0.8$ ) and (b) dry sites (summer $P /$ PET $<0.6$ ). Only the fixed part of the model was used to illustrate the effects. The data presented in each panel correspond to 28 sampled plots and, in each case, the range of axis values corresponds to the range present in each site type.

growth at sites with intermediate dryness (Fig. 6), whereas dry and wet sites showed more similar responses. The interaction between local climate and annual temperature in this new model remained essentially identical to the effect shown in Fig. 5, and it is, therefore, not depicted. It should be noted that although the coefficient for the direct effect of summer $P / P E T$ is negative in Models 3-5 (Tables 2-4), when the interaction terms are considered and multiplied by values of the corresponding variables within the range observed in our study, a positive relationship between summer P/PET and growth is obtained, consistent with the results in Table 1.

Incorporating management into any of the previous models (Models 3-5) according to either of the two definitions presented in the 'Material and methods' neither resulted in a significant effect nor increased the overall fit of the models ( $P>0.2$ in all cases), indicating that the growth response of the different plots was similar regardless of the evidences of management detected at the time of sampling. Models 3-5 captured the temporal variability of the observed BAI, including the stabilization of growth after ca. 1975 (Fig. 3c; $R^{2}$ between observed and modelled annual BAI is 0.91 ), indicating that this stabilization could be explained by changes in the explanatory variables included in the model. In fact, BAI for the last quarter of the 20th century was positively correlated with summer $P /$ PET (Fig. 7; $R^{2}=0.409, P<0.001$ ), indicating that, for that exceptionally warm period, drier summers were strongly associated with lower growth rates. No relationship was found between BAI and the concentration of $\mathrm{CO}_{2}$ for the same period $(P>0.05)$. 
Table 3 Summary of the composite model incorporating local climate effects (Model 4, see text)

\begin{tabular}{lrrrr}
\hline Fixed effects & Estimate & SE & df & $P$-value \\
\hline Intercept & -1.7954 & 0.4385 & 134 & $<0.001$ \\
$D$ & 0.1631 & 0.0085 & 543 & $<0.001$ \\
$D^{2}$ & -0.0059 & 0.0003 & 539 & $<0.001$ \\
$C_{2}$ & 0.0102 & 0.0009 & 18632 & 18632 \\
Summer P/PET (2) & -1.1966 & 0.4458 & 18632 & 132 \\
Temperature (c) & -0.0947 & 0.0315 & 132 & 0.007 \\
Dry local climate & 0.1972 & 0.3123 & 18632 & 0.523 \\
Intermediate local climate & 0.2132 & 0.2579 & 0.410 \\
Summer P/PET $\times$ Temperature & 0.1888 & 0.0522 & 18632 & $<0.001$ \\
Temperature $\times$ Dry local climate & -0.0631 & 0.0199 & 0.002 \\
Temperature $\times$ Intermediate local climate & -0.0375 & 0.0164 & 0.022 \\
\hline
\end{tabular}

Note: The response variable is the natural logarithm of BAI. $D$ is tree diameter reconstructed from wood cores, PET is potential evapotranspiration, and $P$ is precipitation. For climatic effects, (c) indicates that the current year values were used, whereas (2) indicates that the average between current and previous year values were used. For the analysis of local climate effects, humid sites were considered the reference level.

Table 4 Summary of the composite model incorporating local climate effects and $\mathrm{CO}_{2}$ interaction (Model 5, see text)

\begin{tabular}{|c|c|c|c|c|}
\hline Fixed effects & Estimate & SE & $\mathrm{df}$ & $P$-value \\
\hline Intercept & -1.2231 & 0.6023 & 134 & 0.043 \\
\hline$D$ & 0.1660 & 0.0085 & 543 & $<0.001$ \\
\hline$D^{2}$ & -0.0060 & 0.0003 & 539 & $<0.001$ \\
\hline $\mathrm{CO}_{2}$ & 0.0082 & 0.0017 & 18630 & $<0.001$ \\
\hline Summer P/PET (2) & -1.2279 & 0.4461 & 18630 & 0.006 \\
\hline Temperature (c) & -0.0928 & 0.0316 & 18630 & 0.003 \\
\hline Dry local climate & 0.5486 & 0.7175 & 132 & 0.446 \\
\hline Intermediate local climate & -1.3017 & 0.6424 & 132 & 0.045 \\
\hline Summer $P /$ PET $\times$ Temperature & 0.1928 & 0.0523 & 18630 & $<0.001$ \\
\hline Temperature $\times$ Dry local climate & -0.0626 & 0.0202 & 18630 & 0.002 \\
\hline Temperature $\times$ Intermediate local climate & -0.0455 & 0.0167 & 18630 & 0.007 \\
\hline $\mathrm{CO}_{2} \times$ Dry local climate & -0.0012 & 0.0022 & 18630 & 0.582 \\
\hline $\mathrm{CO}_{2} \times$ Intermediate local climate & 0.0051 & 0.0020 & 18630 & 0.010 \\
\hline
\end{tabular}

Note: The response variable is the natural logarithm of BAI. $D$ is tree diameter reconstructed from wood cores, PET is potential evapotranspiration, and $P$ is precipitation. For climatic effects, (c) indicates that the current year values were used, whereas (2) indicates that the average between current and previous year values were used. For the analysis of local climate effects, humid sites were considered the reference level.

\section{Discussion}

Climatic drivers of Scots pine radial growth in Catalonia

According to our results, temperature and water availability during the summer ( $P /$ PET ratio) are the main climatic drivers of Scots pine growth in the study area, in agreement with previous results for Mediterranean and other water-limited regions (Bréda et al., 2006; Macias et al., 2006; Andreu et al., 2007; Sarris et al., 2007). As expected, tree growth responded not only to the precipitation of the current year but also to the amount fallen during the previous 2 years of growth (current plus previous year precipitation) (Gutiérrez,
1989; Sarris et al., 2007). Our results suggest that more important than the amount of precipitation is the relationship between precipitation and potential evapotranspiration $(P / P E T)$ during the summer, in agreement with previous studies showing that Scots pine is strongly limited by the relationship between water availability and demand (Poyatos et al., 2007). Overall, the effect of temperature on growth was negative, but this net effect included a strong interaction with water availability: on wet years higher temperatures resulted in greater BAI, whereas the opposite happened during dry years (Fig. 4). Again this is consistent with a strong water limitation, because high summer temperatures result in higher atmospheric water demand and thus 


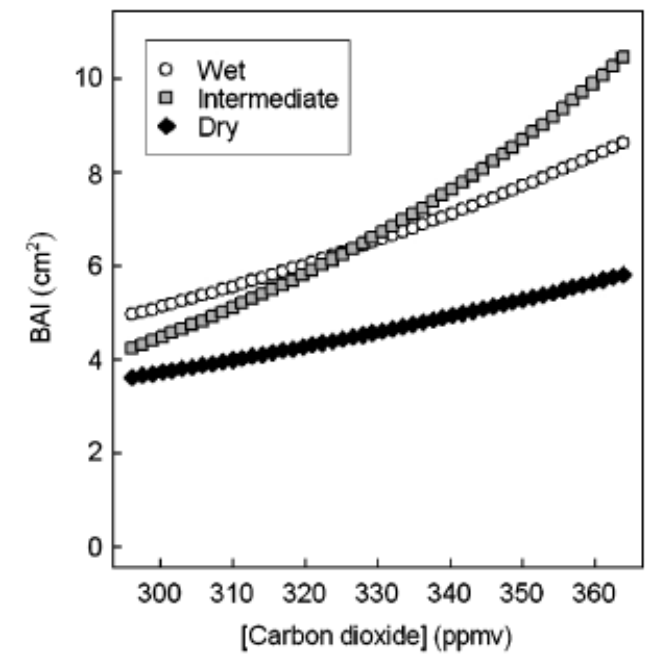

Fig. 6 Relationship between atmospheric $\mathrm{CO}_{2}$ concentration and BAI for wet (summer $P / \mathrm{PET}>0.8$ ), intermediate, and dry sites (summer $P /$ PET $<0.6$ ); predicted according to Model 5 (see text). Only the fixed part of the model was used to illustrate the effects.

greater drought stress. The positive effect of temperature under wetter and cooler conditions (high P/PET), presumably implied that temperature, not water, was limiting under those conditions.

Similar effects were observed when the variability of climatic drivers across space was explored together with the variability in time. Drier sites (lower summer $P /$ PET) had lower growth rates, and were much more sensitive to the negative effect of temperature via increasing PET (Fig. 5). Most dendroecological studies have measured lower radial growth at drier sites, including a recent study on Turkish pine (Pinus brutia) in Greece (Sarris et al., 2007). Also, consistent with our results, Linderholm (2001) found that Scots pine radial growth in Central Scandinavia responded to precipitation only at relatively dry sites. Other authors have also found clear spatial clustering in tree ring and climate responses, in which radial growth responded more markedly to precipitation at drier sites [e.g. Piovesan et al. (2005) for beech (Fagus sylvatica) in Italy, or Carrer et al. (2007) for stone pine (Pinus cembra) in the Alps].

\section{Temporal changes of Scots pine radial growth}

Our results show that the radial growth of Scots pine in NE Spain has increased over the 20th century (Fig. 3). This pattern holds even after taking into account the changes in the size of the trees, which are known to affect growth rates (Table 1). The sign and magnitude of the growth variation are consistent with most previous studies, which consistently show accelerated tree growth in temperate regions over the same period
(Spiecker et al., 1996; Karjalainen et al., 1999; Boisvenue \& Running, 2006), but contrasts with recent work in the Mediterranean region. Sarris et al. (2007), for instance, found a decline in radial growth in P. cembra in the island of Samos (Greece), associated with a decline in precipitation (which has not occurred in our study region, cf. Fig. 2).

In our case, the observed increase in growth was associated with the sustained raise in atmospheric $\mathrm{CO}_{2}$ concentration (Tables 1-4). Similar $\mathrm{CO}_{2}$ fertilization effects have been found in open chamber studies with Scots pine (Ceulemans et al., 2002), and in other detailed studies of tree ring chronologies of several species, including pines (Soulé \& Knapp, 2006; Voelker et al., 2006). The consistency of our results at a relative large, regional scale supports that global factors, such as $\mathrm{CO}_{2}$ and climate, are the main drivers of the observed changes in growth, because the likelihood of other potential causes declines as the spatial scale increases (Parmesan \& Yohe, 2003). However, because of the observational and correlational nature of our study, it is difficult to establish causality from the observed relationships, and alternative explanations for the observed patterns cannot be completely ruled out. It is well known, for instance, that nitrogen deposition has increased during the 20th century over most regions of the Earth, including the studied region (Camarero et al., 2004), and that it can induce increases in tree ring growth (Hättenchwiler et al., 1996). Although there is evidence supporting that the direct effect of increased nitrogen deposition on tree growth may be relatively small (Nissinen \& Hari, 1998; Nadelhoffer et al., 1999), clearly a long-term fertilization effect of $\mathrm{CO}_{2}$ can only be sustained if nutrient availability also increases

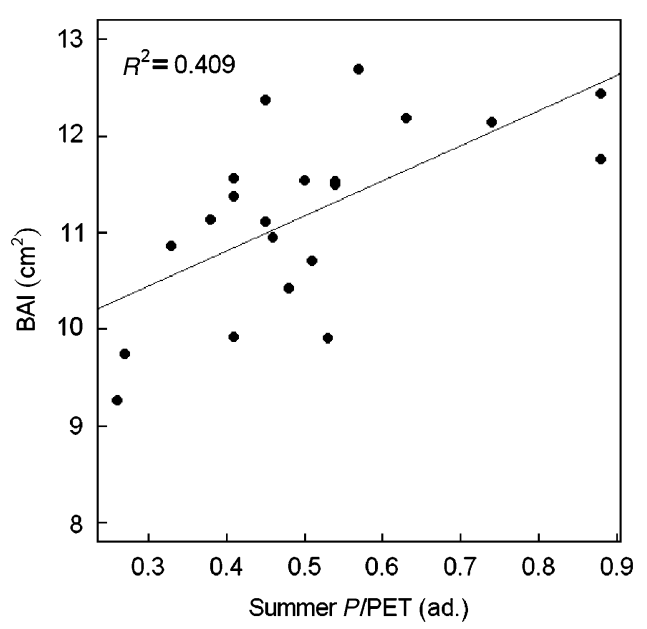

Fig. 7 Relationship between summer $P /$ PET and measured BAI for the last part, and warmest, of the study period (19751995). 
(Hyvönen et al., 2007). Accordingly, the $\mathrm{CO}_{2}$ effect observed in our study is probably best seen as the interactive effect of different drivers, including systematic changes in $\mathrm{CO}_{2}$ concentration, nutrient availability (e.g. increased $\mathrm{N}$ deposition), and temperature (cf. Huang et al., 2007).

Other potential confounding effects in our results are due to a selection bias during sampling (only those trees that survived to the late 20th century were sampled), and changes in the frequency of natural and humancaused disturbances. Several pieces of evidence suggest that these potential artefacts are not critical in our case. Firstly, the large number of sites randomly distributed across the whole range of Scots pine in the study region would tend to minimize any systematic bias in our assessment of growth trends. Secondly, wildfires, arguably the most important 'natural' disturbance over the study region, have not affected Scots pine forests in northern Spain until very recently (from the mid-1990s onwards), subsequent to the time period covered by this study.

Finally, it is known that forest management (and thus demography) has changed over the 20th century in many of the studied sites, potentially affecting forest growth (cf. Rodriguez Murillo, 1997; Chauchard et al., 2007). However, the fact that the main results were strongly consistent and synchronous across sites over a large region, and that they remained unaffected when sites were split according to the current evidences of past management practices, suggests that our main conclusions are robust towards those potential sources of bias. Additionally, it should also be noted that the initial screening of trees removed those showing extraordinary growth patterns resulting, for example, from growth releases following tree cutting; and that, by including plot as a random factor in our models, any idiosyncratic behaviour at the plot level (for instance due to differences in management) was effectively accounted for.

The positive effect on growth that we attributed to $\mathrm{CO}_{2}$ interacted with local climate, so that it was more pronounced at sites with intermediate water availability than at dry or humid locations (Fig. 6). Although these results need to be interpreted with caution for the reasons outlined in the earlier paragraphs, they are largely consistent with the predicted increase in water-use efficiency with increasing $\mathrm{CO}_{2}$ concentration (Wullschleger et al., 2002; Huang et al., 2007). At intermediate humidity sites there is likely to be enough water stress that there is a large gain in growth due to $\mathrm{CO}_{2}$-induced improvements in water-use efficiency or biomass allocation. At humid sites, however, Scots pine forests are probably temperature-, rather than waterlimited, so the potential for $\mathrm{CO}_{2}$ fertilization due to enhanced water economy is smaller. Finally, sites at the drier end of the range are likely to be strongly waterlimited, so that trees may use a more conservative, water-saving strategy, implying very low stomatal conductance (cf. Irvine et al., 1998) that could partially offset the positive effect of increased water-use efficiency on growth. Evidence from tree ring ${ }^{13} \mathrm{C} /{ }^{12} \mathrm{C}$ ratio chronologies supports an increase in water-use efficiency over the 20th century in Scots pine populations from central Siberia (Arneth et al., 2002).

In our study, the apparent $\mathrm{CO}_{2}$ effect over the 20th century occurred simultaneously with an increase in temperature that had an overall negative effect on growth, albeit its magnitude was smaller and did not balance the increase in growth mediated by $\mathrm{CO}_{2}$ (or nutrient availability). Although the substantial warming observed during the 20th century in the study area did not result in a clear pattern of increased drought stress (the summer $P / P E T$ ratio was mostly driven by precipitation and did not change significantly over time, Fig. 2c), this situation is likely to change in the future if climate warming persists. In fact, several studies have already found increased water stress effects on radial growth in pine (Andreu et al., 2007), fir (Abies alba; Macias et al., 2006), and beech (Jump et al., 2006) forests from northern Spain. The fact that the negative effect of temperature on growth was magnified during dry years and at dry sites suggests that the growth trends that have been observed over the 20th century could change depending on the future changes in $\mathrm{CO}_{2}$, temperature, and precipitation amount and distribution. A similar conclusion has been reached by a recent study pooling data from more than 100 common-garden experiments, and showing that the effect of climate warming will be detrimental for growth and survival of Scots pine in all European populations except those in the far north, where the effect will be beneficial (Reich \& Oleksyn, 2008).

If the current trend towards increased precipitation variability that has been observed in Spain (Font Tullot, 1988; De Luis et al., 2000) intensifies in the future, as predicted by most climate models (Sumner et al., 2003; IPCC, 2007), the negative effect of enhanced drought stress on growth could counteract any fertilization effect due to increased nutrient availability, and the temporal trend of increasing growth could even be reversed, as has already been observed in some areas (cf. Barber et al., 2000; Jump et al., 2006; Sarris et al., 2007). Such an effect is suggested in our data by the relative constancy in radial growth observed over the last decades of the 20th century (Fig. 3), coinciding with the period with warmer temperatures (Fig. 2a), and by the strong relationship between BAI and summer drought for that period (Fig. 7). This growth reversal 
is more likely to happen in water-limited ecosystems, such as many of those included in the present study. The consequences for the carbon balance of forests of these direct atmospheric effects on tree growth could be significant, and should be considered together with other possible effects of global change at the community level (e.g. tree dieback, changes in competitive relationships, species substitutions). Some of these effects have been already observed in several Scots pine forests, where recent episodes of high tree mortalities have been associated with acute drought stress (MartínezVilalta \& Piñol, 2002; Bigler et al., 2006).

\section{Conclusions}

Although statistical models such as those implemented in this paper are not appropriate to quantitatively predict future changes in tree or forest growth, due to their lack of mechanistic basis, they can be very useful in identifying recent changes and their likely drivers, and thus providing an indication of future trends. In summary, our results showed an overall increase in Scots pine radial growth in NE Spain during the 20th century, consistent with most previous studies for temperate regions. This trend is likely to be associated with increased atmospheric $\mathrm{CO}_{2}$ concentrations and, possibly, also to a general increase in nutrient availability.

Our results also highlight the importance of considering the interactions among the various drivers of tree growth, because the patterns and the predictions can be very different across sites, even within the range of a single species. The concurrent warming trend that occurred in the study area had a negative impact on radial growth, particularly at the drier sites. Although this warming has not yet resulted in a consistent decline in summer water availability, and the net effect has been dominated by fertilization, the situation may change in the future if temperatures continue to rise and/or precipitation becomes scarcer. This could have broad implications for the carbon balance of forests and their role in sequestering carbon, particularly if the situation is representative of other relatively dry temperate forests, and it is likely to be particularly relevant in a species such as Scots pine, which has shown to be particularly sensitive to recent drought events.

\section{Acknowledgements}

We thank the IEFC staff for collecting and processing all the samples, Josep Anton Sànchez for providing statistical advice, Jordi Vayreda and Santi Sabaté for providing the gridded climatic datasets from the ALARM project, and Josep Piñol, Javier Retana, Diane Pataki, and three anonymous reviewers for providing useful suggestions on an earlier version on the manuscript. This study was supported by the Spanish Ministry of
Education and Science via competitive projects CGL2007-60120 (awarded to J. M. V. and B. C. L.), SHI64-630-VE01-CA02 (M. N.), and MTM2006-01477 (L. B.).

\section{References}

Aber J, Neilson RP, McNulty S, Lenham JM, Bachelet D, Drapek RJ (2001) Forest processes and global environmental change: the effects of individual and multiple stressors on forests. BioScience, 51, 735-751.

Andreu L, Gutiérrez E, Macias M, Ribas M, Bosch O, Camarero JJ (2007) Climate increases regional tree-growth variability in Iberian pine forests. Global Change Biology, 13, 804-815.

Aniol RW (1983) Tree-ring analysis using CATRAS. Dendrochronologia, 1, 35-43.

Arneth A, Lloyd J, Šantrùèková $\mathrm{H}$ et al. (2002) Response of central Siberian Scots pine to soil water deficit and long-term trends in atmospheric $\mathrm{CO}_{2}$ concentration. Global Biogeochemical Cycles, 16, 1-13.

Barber VA, Patrick Juday G, Finney BP (2000) Reduced growth of Alaskan white spruce in the twentieth century from temperature-induced drought stress. Nature, 405, 668-673.

Bigler C, Bräker OU, Bugmann H, Dobbertin M, Rigling A (2006) Drought as an inciting mortality factor in Scots pine stands of the Valais, Switzerland. Ecosystems, 9, 330-343.

Boisvenue C, Running SW (2006) Impacts of climate change on natural forest productivity - evidence since the middle of the 20th century. Global Change Biology, 12, 862-882.

Bréda N, Huc R, Granier A, Dreyer E (2006) Temperate forest trees and stands under severe drought: a review of ecophysiological responses, adaptation processes and long-term consequences. Annals of Forest Science, 63, 625-644.

Budhathoki CB, Lynch TB, Guldin JM (2008) Nonlinear mixed modeling of basal area growth for shortleaf pine. Forest Ecology and Management, 255, 3440-3446.

Burriel JA, Gracia C, Ibàñez JJ, Mata T, Vayreda J (2000-2004) Inventari Ecologic i Forestal de Catalunya, 10 volumes. CREAF, Bellaterra.

Camarero L, Wright RF, Catalan J, Ventura M (2004) Application of MAGIC to Lake Redó (Central Pyrenees): an assessment of the effects of possible climate driven changes in atmospheric precipitation, base cation deposition, and weathering rates on lake water chemistry. Journal of Limnology, 63, 123-132.

Carrer M, Nola P, Eduard JL, Motta R, Urbinati C (2007) Regional variability of climate-growth relationship in Pinus cembra high elevation forests in the Alps. Journal of Ecology, 95, 1072-1083.

Carrer M, Urbinati C (2006) Long-term change in the sensitivity of tree-ring growth to climate forcing in Larix decidua. New Phytologist, 170, 861-872.

Ceulemans R, Jach ME, Van de Velde R, Lin JX, Stevens M (2002) Elevated atmospheric $\mathrm{CO}_{2}$ alters wood production, wood quality and wood strength of Scots pine (Pinus sylvestris L.) after three years of enrichment. Global Change Biology, 8, 153162.

Ceulemans RM, Mousseau M (1994) Tansley Review no. 71: effects of elevated atmospheric $\mathrm{CO}_{2}$ on woody plants. New Phytologist, 127, 425-446. 
Chauchard S, Carcaillet C, Guibal F (2007) Patterns of land-use abandonment control tree-recruitment and forest dynamics in Mediterranean mountains. Ecosystems, 10, 936-948.

Cristóbal J, Ninyerola M, Pons X (2008) Modelling air temperature through a combination of remote sensing and GIS data. Journal of Geophysical Research - Atmospheres, 113, D13106, doi: 10.1029/2007JD009318.

De Luis M, Raventós J, González-Hidalgo JS, Sánchez JR, Cortina J (2000) Spatial análisis of rainfall trends in the region of Valencia (East Spain). International Journal of Climatology, 20, 1451-1469.

Font Tullot I (1988) Historia del Clima en España. Cambios Climáticos y sus Causas. Instituto Nacional de Meteorología, Madrid.

Fritts HC (1976) Tree Rings and Climate. Academic Press, New York.

Grissino-Mayer HD (2001) Evaluating crossdating accuracy: a manual and tutorial for the computer program COFECHA. Tree-Ring Research, 57, 205-221.

Gutiérrez E (1989) Dendroclimatological study of Pinus sylvestris L. in southern Catalonia (Spain). Tree-Ring Bulletin, 49, 1-9.

Hargreaves GH, Samani ZA (1982) Estimating potential evapotranspiration. Journal of Irrigation and Drainage Engineering, 108, 225-230.

Hättenchwiler S, Schweingruber FH, Körner Ch (1996) Tree ring responses to elevated $\mathrm{CO}_{2}$ and increased $\mathrm{N}$ deposition in Picea abies. Plant, Cell and Environment, 19, 1369-1378.

Hódar JA, Castro J, Zamora R (2003) Pine processionary caterpillar Thaumetopoea pityocampa as a new threat for relict Mediterranean Scots pine forests under climatic warming. Biological Conservation, 110, 123-129.

Huang J-G, Bergeron Y, Denneler B, Berninger F, Tardif J (2007) Response of forest trees to increased atmospheric $\mathrm{CO}_{2}$. Critical Reviews in Plant Sciences, 26, 265-283.

Hyvönen R, Ågren GI, Linder S et al. (2007) The likely impact of elevated $\left[\mathrm{CO}_{2}\right]$, nitrogen deposition, increased temperature and management on carbon sequestration in temperate and boreal forest ecosystems: a literature review. New Phytologist, 173, 463-480.

IPCC (2007) Climate Change 2007: the physical science basis. Contribution of Working Group I to the Fourth Assessment Report of the Intergovernmental Panel on Climate Change (eds Solomon S et al.), Cambridge University Press, Cambridge, UK and New York, NY, USA.

Irvine J, Perks MP, Magnani F, Grace J (1998) The response of Pinus sylvestris to drought: stomatal control of transpiration and hydraulic conductance. Tree Physiology, 18, 393-402.

Jump AS, Hunt JM, Peñuelas J (2006) Rapid climate changerelated growth decline at the southern range edge of Fagus sylvatica. Global Change Biology, 12, 2163-2174.

Karjalainen T, Spiecker H, Laroussinie O (eds) (1999) Causes and Consequences of Accelerating Tree Growth in Europe. European Forest Institute, Joensuu, Finland.

Körner Ch (2006) Plant $\mathrm{CO}_{2}$ responses: an issue of definition, time and resource supply. New Phytologist, 172, 393-411.

Linderholm HW (2001) Climatic influence on Scots pine growth on dry and wet soils in the central Scandinavian mountains, interpreted from tree-ring widths. Silva Fennica, 35, 415-424.

Macias M, Andreu L, Bosch O, Camarero JJ, Gutiérrez E (2006) Increasing aridity is enhancing silver fir (Abies alba Mill.) water stress in its south-western distribution limit. Climatic Change, 79, 289-313.

Magee L (1990) $R^{2}$ measures based on Wald and likelihood ratio joint significance tests. American Statistician, 44, 250-253.

Magnani F, Mencuccini M, Borghetti M et al. (2007) The human footprint in the carbon cycle of temperate and boreal forests. Nature, 447, 848-852.

Martínez-Vilalta J, Piñol J (2002) Drought-induced mortality and hydraulic architecture in pine populations of the NE Iberian Peninsula. Forest Ecology and Management, 161, 247-256.

Mencuccini M, Martínez-Vilalta J, Vanderklein D, Hamid HA, Korakaki E, Lee S, Michiels B (2005) Size-mediated ageing reduces vigour in tall trees. Ecology Letters, 8, 1183-1190.

Mitchell TD, Jones PD (2005) An improved method of constructing a database of monthly climate observations and associated high-resolution grids. International Journal of Climatology, 25, 693-712.

Nadelhoffer KJ, Emmett BA, Gundersen P et al. (1999) Nitrogen deposition makes a minor contribution to carbon sequestration in temperate forests. Nature, 398, 145-148.

Ninyerola M, Pons X, Roure JM (2007a) Monthly precipitation mapping of the Iberian Peninsula using spatial interpolation tools implemented in a Geographic Information System. Theoretical and Applied Climatology, 89, 195-209.

Ninyerola M, Pons X, Roure JM (2007b) Objective air temperature mapping for the Iberian Peninsula using spatial interpolation and GIS. International Journal of Climatology, 27, 1231-1242.

Nissinen A, Hari P (1998) Effects of nitrogen deposition on tree growth and soil nutrients in boreal Scots pine stands. Environmental Pollution, 102 (Suppl. 1), 61-68.

Parmesan C, Yohe G (2003) A globally coherent fingerprint of climate change impacts across natural systems. Nature, 421, 37-42.

Piovesan G, Biondi F, Bernabei M, Di Filippo A, Schirone B (2005) Spatial and altitudinal bioclimatic zones of the Italian peninsula identified from a beech (Fagus sylvatica L.) tree-ring network. Acta Oecologica, 27, 197-210.

Poyatos R, Martínez-Vilalta J, Čermák J et al. (2007) Plasticity in hydraulic architecture of Scots pine across Eurasia. Oecologia, 153, 245-259.

Rebetez M, Dobbertin M (2004) Climate change may already threaten Scots pine stands in the Swiss Alps. Theoretical and Applied Climatology, 79, 1-9.

Reich PB, Oleksyn J (2008) Climate warming will reduce growth and survival of Scots pine except in the far north. Ecology Letters, 11, 588-597.

Rodriguez Murillo JC (1997) Temporal variations in the carbon budget of forest ecosystems in Spain. Ecological Applications, 7, 461-469.

Sarris D, Christodoulakis D, Körner Ch (2007) Recent decline in precipitation and tree growth in the eastern Mediterranean. Global Change Biology, 13, 1187-1200.

Saxe H, Cannell MGR, Johnsen Ø, Ryan MG, Vourlitis G (2001) Tansley review no. 123. Tree and forest functioning in response to global warming. New Phytologist, 149, 369-399.

Soulé PT, Knapp PA (2006) Radial growth rate increases in naturally occurring ponderosa pine trees: a late-20th century $\mathrm{CO}_{2}$ fertilization effect? New Phytologist, 171, 379-390. 
Spiecker H, Köhl M, Mielikäinen K, Skovsgaard JP (eds) (1996) Growth Trends in European Forests, EFI Research Report 5. Springer-Verlag, Berlin.

Sumner GN, Romero R, Homar V, Ramis C, Alonso S, Zorita E (2003) An estimate of the effects of climate change on the rainfall of Mediterranean Spain by the late twenty first century. Climate Dynamics, 20, 789-805.

Voelker SL, Muzica R-M, Guyette RP, Stambaugh MC (2006) Historical $\mathrm{CO}_{2}$ growth enhancement declines with age in Quercus and Pinus. Ecological Monographs, 76, 549564.

Weltzin JF, Loik ME, Schwinning S et al. (2003) Assessing the response of ecological systems to potential changes in precipitation. BioScience, 53, 941-952.

Wullschleger SD, Tschaplinski TJ, Norby RJ (2002) Plant water relations at elevated $\mathrm{CO}_{2}$ - implications for waterlimited environments. Plant, Cell and Environment, 25, 319-331. 